\title{
Endoskopska gastrostoma pri otrocih: podatki s Pediatrične klinike v Ljubljani
}

\section{Percutaneous endoscopic gastrostomy in children: data from the Children's hospital in Ljubljana}

Tjaša Žagar, Nataša Podlogar, Matjaž Homan

\section{Izvleček}

Izhodišče: Zadosten vnos hranil je v otroštvu izrednega pomena. $\mathrm{V}$ nekaterih primerih hranjenje in pitje preko ust $\mathrm{ni}$ mogoče oziroma ne zadosti potrebam po hranilih pri otroku. Če napoved izida bolezni ni ugodna in bo otrok predvidoma več kot štiri tedne odvisen od enteralnega hranjenja, je smiselna vstavitev perkutane endoskopske gastrostome (PEG), ki omogoča stalen enteralni dostop.

Metode: Raziskava je bila retrospektivna. Pregledali smo zdravstveno dokumentacijo otrok, ki smo jim vstavili PEG v obdobju od maja 2011 do maja 2019.

Rezultati: $V$ raziskavo je bilo vključenih 124 otrok, od tega $64(51,6 \%)$ fantov. Srednja starost ob vstavitvi PEG je bila 42 mesecev. Večina otrok $(91,9 \%)$ je pred vstavitvijo PEG prejela odmerek antibiotika. Veliko večino otrok $(96 \%)$ smo po PEG začeli hraniti 24 ur po vstavitvi PEG. 57,3 \% otrok, ki smo jim vstavili PEG, je imelo nevrološko bolezen. $V$ povprečju smo primarno gastrostomo zamenjali z nizkoprofilno gastrostomo po petih mesecih. $V$ enem letu po vstavitvi PEG so otroci pridobili telesno maso ( $v$ povprečju $3 \mathrm{~kg}$ ). Od 124 otrok, ki so bili vključeni v raziskavo, je $96(77,4 \%)$ otrok razvilo enega ali več zapletov, povezanih s PEG. Večina zapletov je bila lažjih oziroma prehodnih.

Zaključek: Glede na podatke otrok, ki smo jim v zadnjih 8 letih vstavili PEG na otroški kliniki, lahko zaključimo, da je vstavitev hranilne cevke na endoskopski način varna in učinkovita metoda za zagotavljanje dolgotrajne enteralne prehrane pri kronično bolnih otrocih.

Ključne besede: otroci, vnos hranil, perkutana endoskopska gastrostoma, zapleti.

\begin{abstract}
Background: Adequate nutrient intake is very important in childhood. In some cases, feeding and drinking by mouth are not possible or does not meet the nutrient needs of the child. If the prognosis is not favourable and the child is expected to be dependent on enteral feeding for more than 4 weeks, a percutaneous endoscopic gastrostomy (PEG) should be inserted. This enables constant enteral access.

Methods: The study is retrospective. We reviewed the medical records of children who had a PEG inserted between May 2011 and May 2019.

Results: The study included 124 children, of whom 64 (51.6\%) were boys. The median age at PEG insertion was 42 months. Most children (91.9\%) received a dose of an antibiotic prior to PEG insertion. In the vast majority of children (96\%), feeding through the PEG was instituted 24 hours after PEG insertion. 57.3\% of children who underwent PEG insertion had a neurological disease. The primary gastrostomy was replaced with a low-profile gastrostomy after 5 months. One year after PEG insertion, the children had gained weight (on average $3 \mathrm{~kg}$ ). Out of 124 children enrolled in the study, 96 (77.4\%) developed one or more PEG-related complications, most of which were minor or transient.

Conclusions: Based on the data of children who underwent PEG insertion at the paediatric clinic in the last 8 years, we can conclude that endoscopic insertion of the feeding tube is a safe and effective method of providing long-term enteral nutrition in chronically ill children.
\end{abstract}

Key words: children, nutrient intake, percutaneous endoscopic gastrostomy, complications. 


\section{Uvod}

Zadosten vnos kalorij je posebej v otroštvu izrednega pomena. Zlasti v otroštvu, ko se telo razvija in raste, je odločilen zadosten vnos hranil in energije (1). Kronične bolezni pomembno povečajo potrebo po vnosu hranil, zato včasih zgolj hranjenje preko ust ne zadostuje. Do tega lahko pride pri pomembnih prirojenih boleznih srca, cistični fibrozi in drugih boleznih otroške dobe. Obstajajo tudi bolezni, pri katerih je vnos hranil preko ust otežen ali celo onemogočen. Pogosto se težave s hranjenjem preko ust pojavijo pri otrocih z nevrološkimi boleznimi. Določene bolezni zahtevajo prejemanje številnih zdravil, ki niso prijetnega okusa in jih zato otroci zavračajo. $\checkmark$ vseh omenjenih primerih je smiselno razmisliti o vstavitvi hranilne cev$\mathrm{ke}, \mathrm{ki}$ omogoča varen in zadosten vnos hranilnih snovi v želodec mimo ustne votline. Če pričakujemo, da bo stanje oziroma bolezen, ki zahteva vstavitev hranilne cevke, kratkotrajna, je na mestu vstavitev nosno-želodčne sonde. Če je enteralno hranjenje potrebno več kot štiri tedne, hranilno cevko (gastrostomo) vstavimo skozi trebušno steno v želodec na kirurški ali nekirurški način (2). Sprva so gastrostome vstavljali le kirurgi. Klasični kirurški pristop je zahteval laparotomijo in je bil zato precej invaziven. Manj invazivna kirurška tehnika je laparoskopska vstavitev gastrostome (3). Leta 1980 je Gauderer kot alternativo kirurški tehniki prvič opisal perkutano endoskopsko gastrostomo (PEG) (4). Razlikujemo tri osnovne tehnike vstavljanja PEG, in sicer potezno "pull«, potisno "push" in vbodno "introducer«. Pri vseh tehnikah kateter uvedemo s pomočjo endoskopa brez laparotomije, zato so te tehnike manj invazivne. Na Kliničnem oddelku za gastroenterologijo, hepatologijo in nutricionistiko (KOGHN) Pediatrične klinike v Ljubljani vstavljamo PEG od leta 2005. Najpogosteje uporabljamo potezno tehniko, saj se je izkazala kot uspešna in najbolj varna.
Zdravnik mora otroka, za katerega meni, da je kandidat za vstavitev PEG, predstaviti na Timu za motnje požiranja in prehranjevanja. Tim glede na podatke poda mnenje, ali bi otroku PEG koristila ali ne. Pred vstavitvijo PEG zdravnik starše oziroma skrbnike natančno seznani s posegom ter tudi z morebitnimi zapleti med vstavitvijo PEG in po vstavitvi. Na podlagi vseh prejetih informacij morajo odločitev glede vstavitev PEG poleg tima sprejeti tudi starši oziroma skrbniki, ki morajo svojo privolitev tudi pisno potrditi (3).

Združenje ESPGHAN navaja, da so indikacije za vstavitev PEG pri otrocih (5):

- izboljšanje prehranskega stanja in rasti;

- povečana potreba po hranilih (npr. kemoterapija, radioterapija, presaditev);

- zadosten vnos tekočine;

- zagotavljanje varnega hranjenja oz. preprečevanje aspiracije;

- dekompresija pri parezi želodca;

- izboljšanje sodelovanja pri jemanju zdravil in upoštevanje predpisane diete (npr. pri presnovnih boleznih);

- izboljšanje kakovosti življenja otrok in staršev oz. skrbnikov.

Absolutne kontraindikacije za vstavitev PEG so $(5,6)$ :

- nepopravljive motnje strjevanja krvi (INR > 1,5, PTČ več kot $50 \mathrm{~s}$, št. trombocitov $<50.000 / \mathrm{mm}^{3}$ );

- lega drugih znotrajtrebušnih organov pred želodcem (jetra, debelo črevo itd.);

- vnetje potrebušnice.

Relativne kontraindikacije za vstavitev PEG so $(5,6)$ :

- želodčna razjeda;

- reverzibilne motnje strjevanja krvi;

- predhodne operacije, ki so povzročile adhezije in spremembo lege znotrajtrebušnih organov;

- varice želodca;

- nabiranje tekočine v trebušni votlini;

- kifoskolioza, ki lahko povzroči spremenjeno lego znotrajtrebušnih organov;
- peritonealna dializa;

- ventrikulo-peritonealna drenaža.

Vstavitev PEG pri otroku poteka v endoskopirnici v splošni anesteziji. Po ustrezni predpripravi endoskopist z endoskopom s potezno tehniko vstavi gastrostomo (3).

Po vstavitvi PEG otroci in njihovi starši ali skrbniki ostanejo $v$ bolnišnici vsaj eno noč, še bolje dve noči, da zagotovimo ustrezno analgezijo in varen pričetek hranjenja ter skrbnike naučimo ustreznega rokovanja z gastrostomo in njeno okolico (3). Včasih smo s hranjenjem po PEG začeli šele 24 ur po vstavitvi stome, $v$ zadnjih letih pa so $v$ več raziskavah ugotovili, da je hranjenje po PEG varno že 4-6 ur po vstavitvi (5 7). Hraniti vedno pričnemo postopno z izoosmolarnim enteralnim hiperkaloričnim napitkom, šele po 24 urah pa je varno tudi hranjenje preko ust $z$ navadno hrano, če zato pri otroku ni kontraindikacije.

Prvo prevezo mesta vstavitve PEG opravimo na sterilen način. $V$ prvem tednu je potrebno vsakodnevno prevezovanje, nato pa zadostuje prevezovanje dvakrat na teden do popolne vzpostavitve stomalnega kanala (5).

Najprej dva do tri mesece po vstavitvi PEG, ko se stomalni kanal zaceli in če ni prišlo do zapletov, primarno gastrostomo zamenjamo za nizkoprofilno gastrostomo (5). Menjavo primarne za nizkoprofilno gastrostomo navadno izvedemo $z$ endoskopom. Izjema so gastrostome vrste Covidien, ki jih lahko zamenjamo ambulantno z obturatorjem. Po zamenjavi primarne gastrostome za nizkoprofilno "gumbek« gastrostomo opravljamo menjave "gumbkov« vsakih 6 mesecev v ambulanti otroške klinike, regionalne bolnišnice ali zdravstvenega doma.

Zaplete, povezane s PEG, razdelimo na zgodnje in pozne ter na težje in lažje.

Zgodnji zapleti kot posledica vstavitve PEG se pojavijo v prvem mesecu $(5,8)$. Med zgodnje zaplete sodijo (5):

- zrak v trebušni votlini, 


\begin{tabular}{lr}
\hline Podatki o preiskovancih & 124 \\
\hline skupno število preiskovancev & $64(51,6 \%)$ \\
\hline moški spol & $60(48,4 \%)$ \\
\hline ženski spol & 73 mesecev \\
\hline povprečna starost ob vstavitvi PEG & 42 mesecev \\
\hline srednja starost ob vstavitvi PEG & \\
\hline & Število bolnikov $(\%)$ \\
\hline Osnovna bolezen & $71(57,3 \%)$ \\
\hline nevrološke bolezni & $22(17,7 \%)$ \\
\hline sindromi in genetske okvare & $9(7,3 \%)$ \\
\hline presnovne bolezni & $6(4,8 \%)$ \\
\hline onkološke bolezni & $6(4,8 \%)$ \\
\hline bolezni prebavil & $5(4,0 \%)$ \\
\hline bolezni srca & $3(2,4 \%)$ \\
\hline pljučne bolezni & $2(1,6 \%)$ \\
\hline bolezni ledvic &
\end{tabular}

TABELA 1. DEMOGRAFSKE ZNAČILNOSTI PREISKOVANCEV IN OSNOVNE BOLEZNI OTROK, KI SMO JIM VSTAVILI PEG.

TABLE 1. DEMOGRAPHIC CHARACTERISTICS OF SUBJECTS AND DISEASES IN CHILDREN WHO UNDERWENT PEG INSERTION.

Legenda: PEG - perkutana endoskopska gastrostoma.

- poškodba kolona ali želodčno-črevesna fistula,

- poškodba tankega črevesa,

- zatekanje ob stomi.

Pozni zapleti se pojavijo več kot $30 \mathrm{dni}$ po vstavitvi PEG $(5,8)$ in so $(5)$ :

- okužba ob stomi,

- sindrom preraščanja notranje pelote z želodčno sluznico,

- granulacijsko tkivo.

Med težje zaplete, povezane s PEG, štejemo (5):

- predrtje želodca,

- fistule v sosednje organe,

- razprtje rane,

- vnetje potrebušnice,

- subkutani absces,

- krvavitev,

- vnetje podkožnega tkiva,

- zrak v trebušni votlini,

- sindrom preraščanja notranje pelote z želodčno sluznico.

Lažji zapleti so (5):

- neprehodna stoma,

- izpad hranilne cevke,

- iztekanje želodčne vsebine ob stomi,

- prehodna želodčna pareza,

- želodčna razjeda,

- granulacije,

- okužba na mestu stome.

\section{Material in metode}

Raziskava je bila retrospektivna. Pregledali smo zdravstveno dokumentacijo otrok, ki smo jim vstavili PEG v obdobju od maja 2011 do maja 2019. Zanesljivih podatkov o otrocih z vstavljeno gastrostomo pred letom 2011 nimamo. $V$ zdravstveni dokumentaciji smo poiskali demografske podatke ter podatke o osnovni bolezni, telesni masi in percentilni krivulji pred vstavitvijo PEG in eno leto po vstavitvi. $V$ zdravstveni dokumentaciji smo poiskali tudi podatke o vrsti vstavljene gastrostome, zapletih, povezanih S PEG, času od vstavitve primarne gastrostome do njene menjave, vzrokih za odstranitev gastrostome in času spremljanja otrok. 


\section{Rezultati}

Na KOGHN Pediatrične kinike v Ljubljani smo v osmih letih vstavili 131 hranilnih gastrostom. Od tega smo zaradi pomanjkanja ključnih podatkov $v$ dokumentaciji sedem otrok izključili iz raziskave. Demografske značilnosti preiskovancev in njihove osnovne bolezni predstavljamo v Tabeli 1. Večina otrok, ki smo jim vstavili PEG, je imela nevrološko bolezen (71/124 oz. $57,3 \%)$, od tega je bilo največ otrok s cerebralno paralizo 3.-5. stopnje po motorični lestvici (38/71 oz. $35 \%)$ (Tabela 1).

107 otrok je pol ure pred posegom prejelo odmerek antibiotika cefazolina, otroci pa so prejeli še vsaj en odmerek antibiotika tudi po vstavitvi PEG. Trije otroci so zaradi alergije na cefalosporinske antibiotike oziroma penicilinske antibiotike prejeli klindamicin. Za 10 otrok nimamo podatkov, ali so prejeli antibiotično zaščito ali ne.

Vstavili smo 76 gastrostom proizvajalca Freka ${ }^{\oplus}, 27$ gastrostom Covidien ${ }^{\oplus}$, 3 gastrostome MIC KEY $\mathrm{G}^{\circledR}$ v enem koraku in 1 gastrostomo Corflo ${ }^{\circledR}$, za 17 otrok pa podatka o proizvajalcu nimamo.

119 otrok smo začeli hraniti po PEG približno 24 ur po vstavitvi. Pri dveh otrocih smo zaradi zapletov ob vstavitvi PEG s hranjenjem pričeli 48 ur po posegu oziroma 96 ur po posegu. Za tri otroke nimamo podatkov o tem, koliko časa po vstavitvi PEG smo pričeli s hranjenjem po gastrostomi.

Pri 78 otrok smo opravili elektivno endoskopsko menjavo primarne gastrostome v splošni anesteziji, pri 23 otrocih PA smo menjavo primarne gastrostome opravili ambulantno $z$ obturatorjem. Pri enem otroku smo primarno gastrostomo zamenjali endoskopsko na Gastroenterološki kliniki v Ljubljani. Pri dveh otrocih smo opravili endoskopsko menjavo primarne gastrostome zaradi sindroma preraščanja notranje pelote $z$ želodčno sluznico. Pri 6 otrocih smo PEG odstra- nili pred predvideno menjavo primarne gastrostome zaradi zapletov pri sami stomi ali zaradi zapletov osnovne bolezni. Pri 6 otrocih s slabo napovedjo izida osnovne bolezni primarne gastrostome nismo menjali. Trem otrokom smo vstavili gastrostomo MIC KEY G v enem koraku, pri enem je bila zaradi krvavitve ob vstavitvi potrebna takojšnja menjava gastrostome v enem koraku za primarno gastrostomo. Za 6 otrok nimamo podatkov o menjavi primarne gastrostome. Tako smo primarno gastrostomo elektivno zamenjali 101 otroku. $V$ povprečju smo primarno gastrostomo zamenjali z nizkoprofilno gastrostomo pet mesecev po vstavitvi primarne. Srednji čas do menjave primarne gastrostome je bil štiri mesece. Najprej smo primarno gastrostomo zamenjali s sekundarno en mesec po vstavitvi zaradi sindroma preraščanja notranje pelote $z$ želodčno sluznico. Najkasneje smo primarno gastrostomo otroku zamenjali 30 mesecev po vstavitvi primarne gastrostome.

Podatke o telesni masi in percentilih telesne mase pred vstavitvijo PEG in 1 leto (+/- 3 mesece) po vstavitvi PEG imamo za 96 otrok. Povprečna telesna masa pred vstavitvijo PEG je bila $13,8 \mathrm{~kg}$, povprečen percentil telesne mase pa 11,1. Leto dni (+/- 3 mesece) po vstavitvi PEG je bila povprečna telesna masa $16,8 \mathrm{~kg}$, povprečen percentil telesne mase pa 18,6 , pri čemer smo upoštevali percentilne krivulje UK-WHO.

Otroke smo po vstavitvi PEG v povprečju spremljali 35 mesecev. Srednji čas spremljanja otrok je bil 29 mesecev. Najdlje smo otroka spremljali 107 mesecev po vstavitvi PEG, najmanj pa 4 dni po vstavitvi PEG, kar pomeni, da otroka po odpustu iz bolnišnice nismo več spremljali v naši bolnišnici. Konec maja 2020 smo aktivno spremljali še 65 otrok, 59 otrok pa zaradi različnih vzrokov ne spremljamo več. Gastrostomo smo odstranili 20 otrokom, 19 otrok je umrlo, 6 otrok smo predali internistom. Dva sta si sama izpulila gastrostomo: pri enem smo morali gastrostomo vstaviti ponovno, pri drugem pa se je stanje toliko izboljšalo, da je bilo možno hranjenje preko ust. Za 12 otrok nimamo podatkov.

$V$ osmih letih smo 20 otrokom odstranili PEG. Od tega smo 16 otrokom PEG odstranili zaradi izboljšanja osnovne bolezni. Štirim otrokom smo gastrostomo odstranili zaradi zapletov. Enemu smo gastrostomo odstranili zaradi poslabšanja spastičnosti, pri drugem je prišlo do perforacije želodca s sepso, pri tretjem do ponavljajočega preraščanja notranje pelote $z$ želodčno sluznico, četrti pa je imel vztrajajočo nevtropenijo s ponavljajočimi se sepsami. Pri enem od otrok, ki smo jim odstranili PEG, smo morali stomalni kanal zapirati endoskopsko, saj se ni zaprl spontano.

Od 124 otrok, ki so bili vključeni v našo raziskavo, je $96(77,4 \%)$ otrok razvilo enega ali več zapletov, povezanih s PEG.

Do zgodnjih zapletov, povezanih z vstavitvijo PEG, je prišlo pri 21 od skupaj 124 (16,9\%) otrok. Med njimi sta imela dva otroka zgodnji zaplet, en otrok tri, ostali pa en zgodnji zaplet. Tako je bilo skupno število zgodnjih zapletov 25 . Od zgodnjih zapletov je bilo 12 (48 \%) lažjih zapletov in 13 (52 $\%)$ težjih zapletov (Tabela 2).

Od 119 otok, ki smo jih spremljali več kot mesec dni, je imelo pozne zaplete $87(73,1 \%)$ otrok. 46 otrok je imelo en pozni zaplet, 24 otrok je imelo dva pozna zapleta, tri ali več pozne zaplete je imelo 17 otrok, skupno število poznih zapletov je bilo 160 . Od tega je bilo $143(89,4 \%)$ lažjih zapletov in 17 (10,6 \%) težjih zapletov (Tabela 2$)$.

Kot težje zaplete smo opredelili okužbe, ki so zahtevale intravensko zdravljenje, endoskopsko odstranitev ali menjavo gastrostome in hospitalizacijo. Vnetja, ki smo jih zdravili lokalno, in ostale zaplete, ki smo jih reševali ambulantno, smo šteli za lažje zaplete.

Nihče od otrok ni zapletov, povezanih s PEG, umrl. 


\begin{tabular}{|c|c|}
\hline Zapleti, povezani s PEG & Število zapletov (\%) \\
\hline ZGODNJI ZAPLETI & $25(100 \%)$ \\
\hline težji zapleti & $13 / 25(52,0 \%)$ \\
\hline - vnetje kože in podkožja v okolici stome (i.v. zdravljenje) & $7 / 13(53,8 \%)$ \\
\hline - peritonitis in/ali sepsa & $2 / 13(15,4 \%)$ \\
\hline - večja krvavitev ob vstavitvi PEG & $2 / 13(15,4 \%)$ \\
\hline - pnevmoperitonej & $2 / 13(15,4 \%)$ \\
\hline lažji zapleti & $12 / 25(48,0 \%)$ \\
\hline $\begin{array}{l}\text { - omejeno vnetje v okolici stome (zdravljeno z lokalnim antibiotikom, } \\
\text { antimikotikom) }\end{array}$ & $8 / 12(66,7 \%)$ \\
\hline - poškodba stome & $2 / 12(16,7 \%)$ \\
\hline - podkožni hematom & $1 / 12(8,3 \%)$ \\
\hline - hematom v trebušni mišici & $1 / 12(8 \%)$ \\
\hline POZNI ZAPLETI & $160(100 \%)$ \\
\hline težji zapleti & $17 / 160(10,6 \%)$ \\
\hline - vnetje kože in podkožja v okolici stome (i.v. zdravljenje) & $7 / 17(41,2 \%)$ \\
\hline - sindrom preraščanja notranje pelote z želodčno sluznico & $10 / 17(58,8 \%)$ \\
\hline lažji zapleti & $143 / 160(89,4 \%)$ \\
\hline - razrast granulacijskega tkiva & $56 / 143(39,2 \%)$ \\
\hline - poškodba PEG & $27 / 143(18,9 \%)$ \\
\hline - omejeno vnetje v okolici stome (lokalni antibiotik, antimikotik) & $20 / 143(14,0 \%)$ \\
\hline - zamašitev PEG & $19 / 143(13,3 \%)$ \\
\hline - ponesreči odstranjena/izpadla PEG & $12 / 143(8,4 \%)$ \\
\hline - ulceracije in erozije kože ob PEG & $3 / 143(2,1 \%)$ \\
\hline - erozije na želodčni sluznici ob PEG & $2 / 143(1,4 \%)$ \\
\hline - ektopična želodčna sluznica & $2 / 143(1,4 \%)$ \\
\hline - polipoidna tvorba na želodčni sluznici & $2 / 143(1,4 \%)$ \\
\hline
\end{tabular}

TABELA 2. ZGODNJI ZAPLETI, POVEZANI S PEG (21/124 PREISKOVANCEV JE RAZVILO ENEGA ALI VEČ ZGODNJIH ZAPLETOV), IN POZNI ZAPLETI, POVEZANI S PEG (87/119 PREISKOVANCEV JE RAZVILO ENEGA ALI VEČ POZNIH ZAPLETOV - SKUPAJ 160 POZNIH ZAPLETOV).

TABLE 2. EARLY PEG-RELATED COMPLICATIONS (21 OF THE TOTAL OF 124 SUBJECTS DEVELOPED ONE OR MORE EARLY COMPLICATIONS) AND LATE PEG-RELATED COMPLICATIONS (87 OF THE 119 SUBJECTS DEVELOPED ONE OR MORE LATE COMPLICATIONS - A TOTAL OF 160 LATE COMPLICATIONS) Legenda: PEG - perkutana endoskopska gastrostoma; i.v. - intravensko.

\section{Razpravljanje}

Vstavitev PEG pri otrocih z kroničnimi boleznimi, pri katerih hranjenje in pitje preko ust ni mogoče oziroma ne zadosti povečanim potrebam po hranilih, omogoča zadosten vnos hranil, tekočin in tudi lažji vnos zdravil. S tem lahko izboljšamo potek osnovne bolezni, zmanjšamo število zapletov ter izboljšamo stanje prehranjenosti, razvoja in rasti (1). Na KOGHN v Ljubljani PEG vstavljamo od leta 2005.

$\checkmark$ raziskavo smo vključili otroke s kroničnimi boleznimi, ki smo jim v obdobju od maja 2011 do maja 2019 vstavili PEG. V osmih letih smo PEG vstavili 131 otrokom. Pri otroku z miopatijo črevesa smo vstavili hranilno cevko za razbremenitev želodca. Pri ostalih otrocih smo vstavili gastrostomo zaradi povečanih potreb po kalorijah ali zaradi motenj požiranja in prehranjevanja.

Srednja starost, pri kateri so otrokom v različnih raziskavah vstavili PEG, je bila 24-54 mesecev (4, 8-10). Srednja starost otrok, vključenih v turško raziskavo, je bila 27 mesecev $z$ razponom od 3 mesecev do 192 mesecev (10). Srednja starost otrok, vključenih $v$ islandsko raziskavo, je bila 24 mesecev $\mathrm{z}$ razponom od 1 meseca do 204 mesece (9). $\checkmark$ raziskavi iz Italije je bila srednja starost otrok ob vstavitvi PEG 54 mesecev (8). Na naši kliniki je bila povprečna starost otrok ob vstavitvi PEG 72 mesecev, srednja starost pa 36 mesecev. Najmlajši otrok je bil ob vstavitvi PEG star 1 mesec in 24 dni, najstarejši pa 234 mesecev. Srednja starost preiskovancev ob vstavitvi PEG v naši raziskavi je bila primerljiva s srednjo starostjo preiskovancev v ostalih raziskavah.

Najpogostejša indikacija za vstavitev PEG pri otrocih je nevrološka bolezen (8-10). Najpogostejša nevrološka bolezen, ki zahteva vstavitev PEG, je cerebralna paraliza $(8,10)$. Tudi pri nas je bilo med preiskovanci največ otrok z nevrološkimi boleznimi $(57,3 \%)$, od tega največ otrok $s$ cerebralno paralizo visoke stopnje (35\%). 
Priporočamo, da otroci pred vstavitvijo PEG prejmejo odmerek antibiotika (5, $6,9)$. V več raziskavah so namreč pokazali, da je pojavnost okužb pri tistih, ki so pred vstavitvijo PEG prejeli antibiotik, manjša $(6,9)$. $V$ naši raziskavi je 114 otrok pol ure pred vstavitvijo PEG prejelo odmerek antibiotika, 4 otroci so prejeli vsaj en odmerek antibiotika tudi po vstavitvi PEG. Za 10 otrok podatkov o tem, ali so prejeli antibiotik, nimamo.

$\checkmark$ različnih raziskavah so primerjali varnost zgodnjega hranjenja po PEG. Primerjali so število zapletov pri otrocih, ki so jih po PEG začeli hraniti 6 ur po vstavitvi PEG, in število zapletov pri tistih, ki so jih začeli hraniti tri ure po vstavitvi PEG. Ugotovili so, da se število zapletov ni pomembno razlikovalo $(5,7,11)$. V obdobju, ki ga zajema naša raziskava, smo otroke na naši kliniki po PEG začeli hraniti 24 ur po vstavitvi gastrostome. Izjema sta bila dva otroka, pri katerih smo zaradi zapletov hranjene odložili za 48 ur oziroma za 96 ur. Sredi leta 2019 pa smo glede na nove smernice ESPGHAN (5) tudi na naši kliniki otroke po PEG začeli hraniti že 4 ure po vstavitvi gastrostome.

Menjavo primarne gastrostome $v$ različnih centrih po svetu opravljajo najprej dva meseca do več mesecev po njeni vstavitvi $(5,9,10)$. $V$ dveh mesecih se namreč pri večini otrok dokončno vzpostavi gastrostomalni trakt $(5,6)$. V islandski raziskavi so vsem otrokom primarno gastrostomo zamenjali po dveh mesecih. $V$ turški raziskavi je bil srednji čas menjave primarne gastrostome 8 mesecev (10). $V$ naši raziskavi je bil povprečni čas od vstavitve do menjave primarne gastrostome pet mesecev. Čas do vstavitve nizkoprofilne stome se razlikuje glede na izsledke različnih raziskav, vsekakor pa ne vpliva bistveno na otrokovo zdravje in kakovost življenja.

$\checkmark$ več raziskavah so poročali, da otroci po vstavitvi PEG hitreje in bolje pridobivajo telesno maso (8-10). V italijanski raziskavi s podatki o telesni masi za 45 otrok so spremljali povprečni prirast telesne mase $v$ enem letu po vstavitvi PEG, ki je bil 5 kg (8). $V$ naši raziskavi smo spremljali prirast telesne mase in napredovanje po percentilih telesne mase pri 96 otrocih. Tudi mi smo ugotovili ugoden vpliv vstavitve PEG na pridobivanje telesne mase. Otroci so 1 leto (+/- 3 mesece) po vstavitvi PEG v povprečju pridobili $3 \mathrm{~kg}$ in napredovali za 5,7 percentila telesne mase. $V$ italijanski raziskavi opisujejo za 2 kilograma večji prirast telesne mase $v$ enem letu po vstavitvi PEG (8) kot v naši raziskavi. Razlika gre najverjetneje vsaj delno na račun razlik $v$ vrsti bolnikov $z$ nekoliko drugačno patologijo.

Zapleti, povezani s PEG, so relativno pogosti $(9,12)$. $V$ islandski raziskavi, $v$ kateri je bil srednji čas spremljanja 47 mesecev, so zaplete opisali pri 65 otrok od skupaj 98 otrok, kar je 66,3\%. Od vseh zapletov je bilo $96 \%$ lažjih zapletov in $6 \%$ težjih zapletov. Med lažjimi zapleti je bil najpogostejši zaplet razrast granulacijskega tkiva, med težjimi zapleti pa je bil najpogostejši zaplet peritonitis (9). $V$ danski raziskavi, $v$ katero je bilo vključenih 229 otrok, ki so jih spremljali največ 36 mesecev, srednjega časa pa v prispevku pa ne navajajo, so zaplete opisali pri 118 otrocih $(51,5 \%)(12)$. $V$ naši raziskavi s srednjim časom spremljanja 29 mesecev je od 124 otrok, ki so bili vključeni v raziskavo, $96(77,4 \%)$ otrok razvilo enega ali več zapletov, povezanih s PEG. Število vseh zapletov, povezanih s PEG, zgodnjih in poznih, je bilo skupaj 185, od tega je bilo $25(13,5 \%)$ zgodnjih in $160(86,5 \%)$ poznih. Lažjih zapletov je bilo $155(83,7 \%)$, težjih zapletov pa 30 (16,2 \%). Najpogostejši lažji zaplet je bil razrast granulacijskega tkiva. Najpogostejši težji zaplet je bilo vnetje kože ali podkožja v okolici PEG, ki je zahtevalo intravensko antibiotično zdravljenje. V primerjavi z islandsko in dansko raziskavo je pri nas prišlo do zapletov pri večjem deležu otrok $(77,4$ $\%$ v primerjavi s $66,3 \%$ oziroma 51,5 $\%)$. $V$ vseh treh omenjenih raziskavah je do zapletov, povezanih s PEG, prišlo pri razmeroma velikem številu otrok, a je šlo večinoma za lažje zaplete, ki smo jih zdravili ambulantno. Vzrok večjega števila zapletov $v$ naši raziskavi v primerjavi z dansko je verjetno vsaj delno časovno obdobje spremljanja otrok po vstavitvi PEG. $V$ danski raziskavi so otroke spremljali krajši čas kot $v$ naši raziskavi, a to verjetno ne pojasnjuje manjšega deleža zapletov $v$ islandski raziskavi, v kateri so otroke spremljali dlje kot mi. Na KOGHN imamo zaposleno gastrostomalno terapevtko, ki je staršem in skrbnikom otrok s PEG dostopna vsak delavnik in $\mathrm{v}$ zdravstveno dokumentacijo beleži vsak zaplet, o katerem ji poročajo. Vsaj delno bi tudi to lahko bil vzrok večjega števila zapletov $v$ naši raziskavi.

\section{Zaključek}

$\checkmark$ prispevku smo predstavili podatke otrok, katerim smo v zadnjih osmih letih vstavili hranilno gastrostomo na endoskopski način. Zaključimo lahko, da je ob upoštevanju ustreznih indikacij in kontraindikacij vstavitev PEG varna in učinkovita metoda, ki omogoča dolgotrajen enteralni dostop. Zapleti se sicer pojavljajo pogosto, a gre večinoma za blage zaplete, ki ne zahtevajo sistemskega zdravljenja.

\section{Literatura}

1. Szlagatys-Sidorkiewicz A, Bor-

kowska A, Popinska K, Toporowska-Kowalska E, Grzybowska-Chlebowczyk U, Wernicka A, Hapyn E et al. Complications of PEG are not related to age - The result of 10-year multicenter survey. Adv Med Sci 2016; 61(1): 1-5.

2. Islek A, Sayar E, Yilmaz A, Artan R. Percutaneous endoscopic gastrostomy in children: is early feeding safe? J Pediatr Gastroenterol Nutr 2013; 57(5): 659-62.

3. Štemberger Kolnik T, Majcen Dvoršak S, Kaučič MB, Klemenc D. Celostna obravnava pacienta $z$ gastrostomo in jejunostomo in posebnosti prehranjevanja: zbornik predavanj. Zbornica zdravstvene in babiške nege Slovenije, Zveza strokovnih društev medicinskih sester, babic in zdravstvenih tehnikov Slovenije in Sekcija medicinskih sester v enterostomalni terapiji; 2009.

4. Balogh B, Kovacs T, Saxena KA. Complications in children with percutaneous endoscopic gastrostomy (PEG) placement. World J Pediatr 2019; 15(1): 12-6. 
5. Heuschkel RB, Gottrand F, Devarajan K, Poole $\mathrm{H}$, Callan J, Dias JA et al. ESPGHAN Position paper on management of percutaneous endoscopic gastrostomy in children and adolescents. J Pediatr Gastroenterol Nutr 2015; 60(1): 131-41.

6. Fröhlich T, Richter M, Carbon R, Barth

$B$, Köhler H. Review article: percutaneous endoscopic gastrostomy in infants and children. Aliment Pharmacol Ther 2010;.31(8): 788-801.

7. Wiernicka A, Matuszczyk M, Szlagatys-Sidorkiewicz A, Landowski P, Toporowska-Kowalska E, Gebora-Kowalska B, Popinska K et al. Tolerability and safety of early enteral nutrition in children after percutaneous endoscopic gastrostomy placement: A multicentre randomised controlled trial. Clin Nutr 2019; 38(4): 1544-8.

8. Di Leo G, Pascolo P, Hamadeh K, Trombetta A, Ghirardo S, Schleef J et al. Gastrostomy placement and management in children: a single-center experience. Nutrients 2019; 11(7): 1555.

9. Viktorsdóttir MB, Óskarsson K, Gunnarsdóttir A, Sigurdsson L. Percutaneous endoscopic gastrostomy in children: a population-based study from iceland, 1999-2010. J Laparoendosc Adv Surg Tech A 2015; 25(3): 248-51.

10. Koca T, Sivrice AC, Dereci S, Duman L, Akçam M. Percutaneous endoscopic gastrostomy in children: a single center experience. Turk Pediatri Ars 2015; 50(4): 211-6.

11. Corkins MR, Fitzgerald JF, Gupta SK. Feeding after percutaneus endoscopic gastrostomy in children: early feeding trial. J Pediatr Gastroenterol Nutr 2010; 50: 625-7.

12. Hansen E, Qvist N, Rasmussen L, Ellebaek MB. Postoperative complications following percutaneous endoscopic gastrostomy are common in children. Acta Paediatr 2017; 106(7): 1165-9. izr. prof. Matjaž Homan, dr. med.

(kontaktna oseba/contact person)

$\mathrm{KO}$ za gastroenterologijo, hepatologijo in nutricionistiko

Pediatrična klinika

Medicinska fakulteta v Ljubljani

Univerzitetni klinični center Ljubljana

Bohoričeva 20

1525 Ljubljana, Slovenija

e-naslov: matjaz.homan@guest.arnes.si

Tjaša Žagar, dr. med.

Splošna bolnišnica Novo mesto - KO za nevrologijo, Novo mesto, Slovenija

Nataša Podlogar, m. s.

$\mathrm{KO}$ za gastroenterologijo, hepatologijo in nutricionistiko, Pediatrična klinika, Ljubljana, Slovenija

prispelo / received: 22. 3. 2021

sprejeto / accepted: 27. 9. 2021

Žagar T, Podlogar N, et.al. Endoskopska gastrostoma pri otrocih: podatki s Pediatrične klinike v Ljubljani. Slov Pediatr 2021;

28(3): 123-129. https://doi.org/10.38031/ slovpediatr-2021-3-01. 